\title{
Children's Rights, Educational Research and the UNCRC: Past, present and future, edited by Jenna Gillett-Swan and Vicki Coppock
}

Oxford: Symposium Books, 2016, I66pp., $€ 36$ (pbk), ISBN: 978-I-873927-95-3

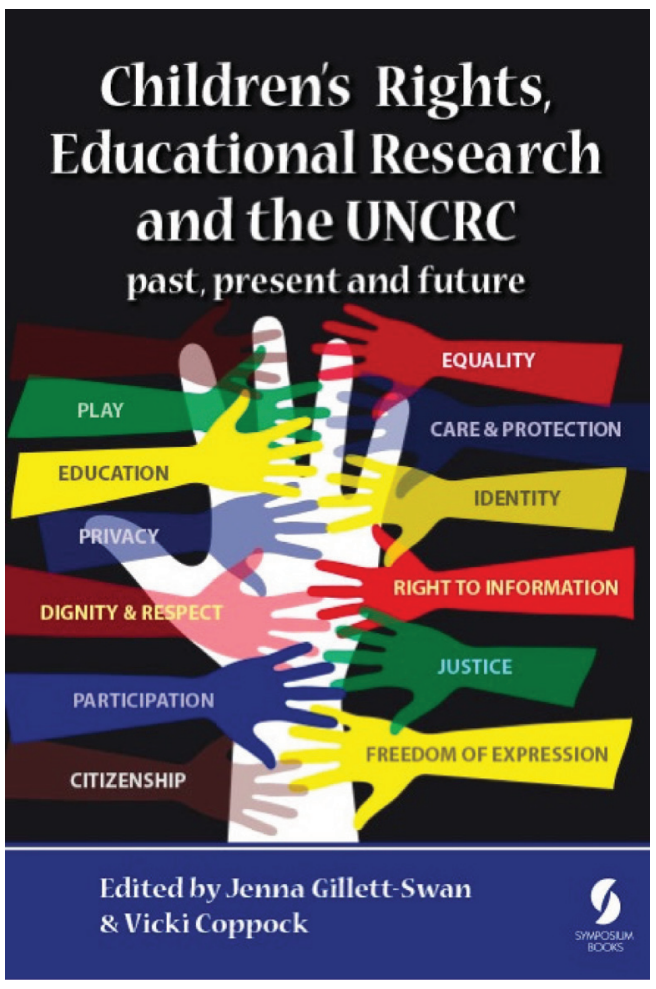

This book review is the culmination of a collaborative project between a group of students studying for the MA in Sociology of Childhood and Children's Rights at UCL Institute of Education, University College London. After having read Children's Rights, Educational Research and the UNCRC, we took part in a workshop to learn more about book reviews and how to craft them, facilitated by Rachel Rosen, the Programme Leader. Each student then chose a chapter of the book to review, and these reviews follow below. In this first section, I outline the book, before examining some of the ideas explored in the Introduction.

This book came about as a result of the European Educational Research Association annual conference. During this conference, Gillett-Swan and Coppock chaired a roundtable discussion of Network 25, which is dedicated to children's rights in education. This volume brings together a selection of papers from the round table. It is designed to bring together recent thinking about children's rights in educational research, and to appeal to a broad audience of both researchers and educational practitioners. Crucially, the chapters cover an international selection of countries, but only from the minority world. Given debates about the applicability of a single model of childhood, often based on minority world assumptions, and global inequalities in the production of knowledge in childhood research, this is a significant gap. It also raises questions as to whether the book is truly representative of 'diverse and wide-ranging contexts' (I0), as the editors claim.

The Introduction sets out some of the key themes to be addressed in the book through a structure that echoes the subtitle: past, present and future. The editors introduce the United Nations Convention on the Rights of the Child (UNCRC) and the field of children's rights (the past), before giving an overview of three present debates. These are the drive towards children's participation rights, which draws upon the sociology of childhood for the conceptual shift that has occurred towards viewing children as social actors, the 'dichotomy' of children's rights and parental rights (9) and debates surrounding the decontextualization of children's rights from children's lived experiences. Their summary is perhaps a little undeveloped for researchers in the field, but makes the volume more accessible to readers who are unfamiliar with current debates, fitting well with the intended audience. The future is addressed by proposing to move through and beyond the UNCRC when contextualizing children's rights in education, such as the necessity for adaptability in children's rights research agendas going forward and availing of the possibilities of digital media. The past, present and future structure is useful in that it helps to guide the reader carefully through what could easily become dense theory. However, it does 
leave us with a linear narrative approach to children's rights, which has a danger of slipping away from critique towards description and acceptance.

I will leave it to my fellow reviewers to decide whether the chapters within this volume address the key themes set out here.

Katherine J. Lee

\section{Chapter I. John L'Anson. UNCRC at 25: A critical assessment of achievements and trajectories with reference to educational research}

This chapter successfully conceptualizes the multiple ways in which the UNCRC overlaps with educational research and how this has influenced international educational research in the past, how it has impacted on current research and how it might factor into future research. The author clearly articulates the importance of considering how the UNCRC is 'translated' in practice and procedures: in other words, how the intentions and meanings of specific Articles are realized across diverse cultures and multiple childhoods. Although this is not a new point, the chapter is worthy of inclusion in the book as it identifies the importance of finding ways of moving beyond negative critique. John L'Anson advocates exploring the advantages of alternative perspectives and highlights the benefits of learning from themes found within different approaches, both their insights and limitations.

L'Anson provides a realistic overview of the challenges and benefits that the UNCRC brings to educational research. For instance, in the 'Extending Rights' (23) section, he traces one major theme in children's rights research with regard to early years practice and the research process. He highlights scholarship that demonstrates the authority and capacity children have to articulate effectively and extensively on social life as children rather than as subjects of adult observation. This stimulates further consideration of the importance of gathering data directly from children, rather than just focusing on assumptions made by adults about the lives of children. At the same time, he highlights the difficulties in doing so, such as including diverse children and multiple stakeholders.

The assertion of the validity of children's perceptions has prompted me, as a master's student of Sociology of Childhood and Children's Rights, to include the children who participated in my dissertation research in the data analysis process. By doing this, we have been able to identify themes that may not have emerged if children had not been involved. One such theme relates to 'subcultures' within peer groups, which are not always visible to adult researchers, teachers or parents.

Jacqueline Woodford

\section{Chapter 2. Louise Gwenneth Phillips. Educating Children and Young People on the UNCRC: Actions, avoidance and awakenings}

The poignant title of Phillips's chapter highlights an array of responses to a Convention that was heralded as a tool to advance the rights of children. The chapter aims to construct a picture of how the UNCRC has been made accessible to those it envisions protecting, drawing on Article 42, which places an onus on states to make the convention widely known to all. The chapter includes an overview of active steps taken to achieve this, while acknowledging the limits of good practice (actions); criticisms of those who have not done enough (avoidance); and a stark reminder that only a small percentage of children have been affected by these initiatives (awakenings). 
Although Phillips repeatedly reminds us that the chapter cannot provide comprehensive coverage of global initiatives, crucial to her argument, yet noticeably absent, is a discussion of how avoidance has affected children who are particularly marginalized. My MA research on Black British girlhood, for instance, has emphasized that the assumptions we hold to be true about children tend to ignore the multiple intersections that cross-cut childhood experiences, such as 'race', 'gender' and 'class'. Many of the examples of good practice in the chapter are of initiatives taking place in Eurocentric school settings, potentially leaving many children at the margins of the discussion. Focusing on actions in these settings runs the risk of advancing a tradition of neglect of certain groups of children and reproducing inequalities.

Phillips's conclusion is two-fold. She reminds us of the historically low status of children and then asks us to draw on the broad range of information technology available as a tool to help children find out about their rights. Again, this is a missed opportunity to offer a nuanced awakening to intersectional childhood, and recognition of those who may not have access to 'YouTube clips, memes and vines' (55).

These points aside, Phillips makes a compelling case, reminding us that the UNCRC is regrettably not enough to advance the rights of children. Phillips challenges us (adults) to do something worthwhile with this knowledge: recognize children as social actors worthy of knowing and understanding their rights.

Christine John

\section{Chapter 3. Nina Thelander. Human Rights Education: Teaching children's human rights - a matter of why, what and how}

The aims of this chapter are to explore what human rights education is, why it is important and how it could be addressed in schools. To achieve that, Thelander draws on the UNCRC as well as the World Programme for Human Rights Education (HRE), going on to illustrate HRE in action based on empirical data in two Swedish schools. She further argues that current global and national problems could be addressed through the implementation of good HRE.

HRE consists of knowledge and skills; values, attitudes and behaviour; and action. In the Swedish context, according to this chapter, the first aspect means awareness of the articles of the UNCRC. In terms of values, Swedish teachers mention that they try to engage children in group projects and encourage them to express their opinions freely and listen to the views of others so as to gain democratic values. In terms of action, Swedish teachers state again the importance of the UNCRC.

Thelander certainly fulfils the aims she sets at the beginning of the chapter. The beginning of the chapter is a bit descriptive, but the later part of it, where she critically engages with HRE in relation to Swedish schools, is more interesting. In fact, she effectively shows how theory could be applied to practice. However, the examples are based on interviews with only two teachers, which means that we do not gain a holistic perspective of the Swedish context. I was also expecting to see some proposals of what could be done to improve the way HRE is addressed in schools.

Thelander primarily focuses on good HRE practices in Swedish classrooms. But, reflecting on the absence of HRE in other countries, as has been my experience as a student and teacher in Greece, suggests that school context is also important. It seems that schools cannot address HRE on their own: wider financial, political and social support is also needed. 


\section{Chapter 4. Reetta Niemi, Kristiina Kumpulainen and Lasse Lipponen. Pupils' Participation in the Finnish Classroom: Turning the UN Convention on the Rights of the Child into pedagogical practices}

This chapter explores children's engagement in the pedagogical practices of the classroom in a Finnish primary school. The authors introduce three models of participation (from Hart, Shier and Lundy), and then discuss how these are reflected in the Finnish national curriculum and pedagogical practices. They argue that the UNCRC and children's participation can be realized in lived pedagogical practices, including the three approaches discussed in the chapter. In the diamond-ranking method, children take and rank photographs in descending order of positive classroom practices. In group meetings, students and teachers discuss everyday life problems. In narrative learning projects, students document and reflect on learning. The authors argue that all three methods offer children a chance to express their perceptions in multiple ways. This supports and encourages children's classroom participation in line with Articles 12 and 13 of the UNCRC.

For my master's dissertation, I adopted a similar approach to diamond-ranking: photograph elicitation. My child participants took photographs to express their perspectives about afterschool outdoor play in urban environments. I found that children enjoyed participating when they had the opportunity to take photographs. However, there are some drawbacks to photoelicitation/diamond-ranking activities. They can make children feel as though there is a 'correct' answer or put undue pressure on them, since they may not know how many pictures they need or what to include in pictures. In other words, methods that seem participatory and welcoming may not always be experienced by children in that way. The success of methods also has to do with relationships between researchers and participants, and the ways in which research activities are introduced. Another challenge is that these approaches may not be suitable in all contexts, such as in China, where I conducted my MA research. Large class sizes and varying ideas about childhood mean that such methods can work and be experienced differently. I would have liked the authors to discuss issues of context, relationships and presentation of methods in more detail.

Xiaowen Han

\section{Chapter 5. Joana Lúcio and Fernando Ilídio Ferreira. Children's Rights in Times of Austerity: Social awareness of pre-service teachers in Portugal}

This chapter engages effectively with the issue of children's rights in a context affected by social and economic contractions: Portugal. Lúcio and Ferreira provide a meticulous study about how children's right to civic participation is treated with scepticism in periods of social and economic insecurity. They accomplish this through analysis of pre-service teachers' approaches to social and political education for children. Simultaneously, the authors critique changes at universities in Portugal resulting from the Bologna Process, including more didactics and less general education in the training curricula.

The chapter constitutes an important addition to an international bibliography concerned with education and economic issues. The authors produce a much-needed analysis of austerity measures, including reductions in employment, increases in consumption taxes and social contributions, and reversals of the education allowance. They point to deleterious implications for families', children's and teachers' lives in Portugal, including high youth unemployment, jobless households and early school leaving. Unlike many studies that suggest that challenges in achieving children's rights in schools are problems of implementation or moral commitment, 
these authors make clear that it is not possible to achieve children's rights without attending to wider contexts.

The economic and political approach demonstrated in relation to children's rights and education makes me think differently about the current situation in Greece, where I am doing my MA research. The implications of the economic crisis and austerity policy for the Greek educational system are indubitable. Lúcio and Ferreira's chapter functions as a valuable guide for my dissertation about refugee children's schooling in Greece. It helps me to interpret the Greek state's struggles to respond to refugee children's needs. For example, although Greek state schools have offered Greek lessons to refugee children, there have not been resources to adapt the curriculum to refugees' concerns and values. The chapter helped to put this in the context of the Greek educational system's frailness in times of austerity.

Markella Grigorakou

\section{Chapter 6. Gordon Tait and Mallihai Tambyah. Rights without a Remedy? Children's privacy, social governance and the UNCRC}

In their chapter, Gordon Tait and Mallihai Tambyah attend to Article 16 of the UNCRC, the right to privacy. They critique Article 16, arguing that it has no legal remedies, particularly in light of the massive increase in the use of 'big data' for surveillance and supervision of children. They follow Foucault in positioning childhood as a highly regulated space controlled by the state through disciplinarian techniques, which are then subsumed by children. The state thereby exerts control on the becoming of future generations. This regulation, achieved through measuring, testing and record keeping, has become almost infinite due to the capacities of modern technologies. It is in direct conflict with current notions of privacy - a paradox that lies at the heart of the chapter. Nevertheless Tait and Tambyah extol the importance of Article 16 in providing a symbolic standard for privacy rights, despite the absence of legal mechanisms to support them.

The authors highlight how this tension is exacerbated by adult-child power relations. A desire for private interactions with peers outside of the observation of those in dominant social positions is currently seen as a right for adults, and yet children are often 'protected' from this right. In my own professional practice in adventure play, I have seen the curtailing of children's den-building because these places cannot be seen at every given moment. Constant supervision has become a societal expectation. Parents demand it, as do council funders, yet children continue to ask for space of their own where they are not watched, monitored, judged and controlled.

The pressure of living under constant surveillance, which is then documented, retained and potentially shared with future employers and educators can be a stress on individuals and an infringement of rights. Tait and Tambyah provide a way to challenge this. By positioning privacy as an 'evolving historical construct' (I35) they remind the reader that childhood itself is also a construct influenced by time and place, rather than a natural and given state. Thus, childhood has the capacity to be reconstructed differently, as does privacy, possibly in a way where 'the right to be left alone' becomes a real expectation for children as well as adults (I30). 


\section{Chapter 7. Jenna Gillett-Swan and Vicki Coppock. The Future of Children's Rights, Educational Research and the UNCRC in a Digital World: Possibilities and prospects}

This chapter explores the future of children's rights and how technology or, in other words, the 'digital world', shapes children's lives. The authors argue that the expansion of technology has helped children express themselves (UNCRC, Article 13) and gain access to diverse sources of information (UNCRC, Article 17). They contend that digital technology can be empowering; it can also support education on children's rights. However, there are safety and privacy concerns due to the growth of digital media, which threaten children's protection rights. For example, it is difficult to control the spread of images that children post of themselves and their friends on social media sites. It is unfortunate that the authors did not address these ambiguities of digital media - that it can be both risky and increase participation rights. That said, although the authors spent limited time discussing the more troubling aspects of digital media, their focus on its positive value provides a welcome shift from much popular debate, which focuses primarily on the risks.

A key concern of the chapter is about access, namely that some children may have access to technology and others may not. If digital media are a powerful source of information, expression and rights education, differential access to technology may lead to some children's participation rights being achieved while the rights of others are denied. Despite these important points made by Gillett-Swan and Coppock, I suggest that we need to make a distinction between access to technology and fundamental rights. First, if fundamental rights are about ensuring conditions for a minimally good life, then there are other far more pressing needs than technology for many children in majority world contexts. These include clean water and food for survival, optimal health, and safety. Second, digital technologies are only one way to access information and exercise participation rights, and we would not want to reduce these important rights simply to digital technologies. For example, children gain information and participate in community life through a variety of activities, such as learning about climate change at a science museum.

Kubra Gul

Students on the MA in Sociology of Childhood and Children's Rights UCL Institute of Education, University College London r.rosen@ucl.ac.uk

\section{Note}

Students on the MA in Sociology of Childhood and Children's Rights (SCCR) at UCL Institute of Education, University College London, are often the intended audience for books such as Children's Rights, Educational Research and the UNCRC, but they are not typically invited to contribute to traditional review processes. More importantly, they often have relevant and significant insights about scholarship in this field based on their own original dissertation research and professional practice. Recognition of these points motivated the MA SCCR teaching team to facilitate and support the writing of collaborative book reviews as a voluntary part of the degree. For more information about the MA SCCR, see www.ucl.ac.uk/ioe/courses/graduate-taught/ sociology-childhood-childrens-rights-ma or contact Dr Rachel Rosen, the Programme Leader, r.rosen@ucl.ac.uk. 